\title{
A PROFISSÃO DO AUDITOR E O PERITO CONTÁBIL NA VISÃO DOS ACADÊMICOS CONCLUINTES DO CURSO DE CIÊNCIAS CONTÁBEIS DE UNIVERSIDADE PÚBLICA E PRIVADA DE TANGARÁ DA SERRA/MT
}

\author{
Vanderléia Aparecida da Silva ${ }^{1}$ \\ Carlos Edinei de Oliveira ${ }^{2}$ \\ Paulo Guimarães Camelo ${ }^{3}$ \\ Edinéia Souza Nunes ${ }^{4}$ \\ André Gomes Carvalho ${ }^{5}$
}

\section{Resumo}

Este artigo tem como objetivo verificar a visão dos acadêmicos concluintes em relação à profissão de auditor e de perito contábil e algumas das semelhanças e diferenças existentes entre as duas profissões; pois, diante das amplas opções que um profissional da área contábil tem, essas são duas profissões importantes e se assemelham quanto aos procedimentos, mas diferenciam-se quanto aos objetivos e finalidades. O embasamento teórico foi realizado a partir de pesquisa bibliográfica e por meio de artigos e livros publicados sobre o tema cujo público-alvo são os alunos do oitavo semestre do curso de Ciências Contábeis de uma universidade privada e outra pública. Para obtenção dos dados, foram aplicados questionários, utilizando-se a abordagem qualitativa, para que os respondentes possam expressar suas opiniões em relação à grade curricular e também sobre o conhecimento da profissão. Para tanto, elaboraram-se tabelas e depois se analisaram os resultados obtidos com a pesquisa. Ao final da análise dos dados, concluiu-se que os acadêmicos consideram as profissões como promissoras e com grandes oportunidades, mas, segundo eles, a formação acadêmica não lhes proporciona práticas para que possam conhecer aprofundadamente as carreiras por que podem optar após a formação.

Palavras-chave: Auditoria Contábil; Perícia Contábil; Acadêmicos de Contabilidade.

\section{INTRODUÇÃO}

O mercado de trabalho está cada vez mais exigente e competitivo, pois as informações mudam rapidamente. Com o avanço da tecnologia, surgem novos desafios, métodos, processos operacionais e mudanças na área contábil trazendo mais eficiência às informações e agilidade nos processos. $\mathrm{Na}$ área da contabilidade, o domínio dessas inovações permite mais

\footnotetext{
${ }^{1}$ Especialista em Auditoria e Perícia Contábil, professora do curso de Ciências Contábeis da UNEMAT Campus de Tangará da Serra, e-mail: vanderleia2908@ hotmail.com

${ }^{2}$ Professor Orientador, Dr. Carlos Edinei de Oliveira, e-mail: carlosedinei@unemat.br

${ }^{3}$ Professor de Matemática, e-mail: paulocamelo.tga@ hotmail.com

${ }^{4}$ Especialista em Auditoria e Perícia Contábil, pesquisadora DTI - CNPQ - UNEMAT- Campus de Tangará da Serra, e-mail: edineiaqueroz@ hotmail.com

${ }^{5}$ Especialista em Gestão de Pessoas, e-mail: agc.andre@ gmail.com

Volume 3, Número 6

Revista UNEMAT de Contabilidade 
A profissão do auditor e o perito contábil na visão dos acadêmicos concluintes do curso

de Ciências Contábeis de universidade pública e privada de Tangará da Serra/MT

Vanderléia Aparecida da Silva; Carlos Edinei de Oliveira; Paulo Guimarães Camelo; Edinéia

Souza Nunes; André Gomes Carvalho

eficiência nas informações e agilidade nos processos necessários ao bom andamento dos serviços.

A profissão de auditor contábil e de perito contábil transformou-se em assunto atual e de fundamental importância para a tomada de decisões, independentemente do tamanho ou segmento da empresa; no entanto, os acadêmicos concluintes do curso de Ciências Contábeis de uma universidade privada e de uma universidade pública possuem dúvidas quanto à formação, sobretudo à diferenciação desses profissionais.

Por meio desta pesquisa, foi possível verificar que são duas áreas de atuação muito confundidas, principalmente pelos leigos no assunto. Este trabalho pode sanar muitas dúvidas de quem tiver acesso a ele, pois as informações que traz contribuem ao entendimento, pois, além das explicações, foi feito uma comparação entre as duas profissões.

A pesquisa foi feita por intermédio de questionário cujas respostas eram de escolha simples (sim ou não), a fim de identificar as perspectivas dos acadêmicos concluintes em relação a essas profissões. Este estudo será importante para as instituições de ensino, visto que poderão ter conhecimento quanto aos acadêmicos que saem da universidade, podendo prepará-los para ser profissionais bem conceituados no mercado e, talvez, optando por uma dessas carreiras profissionais.

Sendo assim, os objetivos deste artigo foram identificar a importância da profissão do auditor contábil e do perito contábil no mercado atual, a visão dos acadêmicos em relação a essas profissões e as oportunidades no mercado de trabalho. Ao mesmo tempo, averiguar se as grades curriculares lhes proporcionaram alguma experiência quanto às possibilidades que a profissão oferece, se os alunos sabem o que faz um auditor ou um perito contábil. Complementa-se o estudo com uma breve comparação das duas profissões a partir de quadros comparativos.

Dessa forma, este trabalho de pesquisa faz-se relevante à medida que é possível conscientizar e informar os acadêmicos sobre essas duas áreas de atuação e sua importância para as tomadas de decisões das empresas e também para a sociedade. 
A profissão do auditor e o perito contábil na visão dos acadêmicos concluintes do curso

de Ciências Contábeis de universidade pública e privada de Tangará da Serra/MT

Vanderléia Aparecida da Silva; Carlos Edinei de Oliveira; Paulo Guimarães Camelo; Edinéia

Souza Nunes; André Gomes Carvalho

\section{FUNDAMENTAÇÃO TEÓRICA}

\subsection{Auditoria}

De forma bastante simples, pode-se definir auditoria como o levantamento, estudo e avaliação sistemática das transações, procedimentos, operações, rotinas e das demonstrações financeiras de uma entidade (CREPALDI, 2011, p. 3).

A auditoria é a forma pelo qual o auditor certifica-se da veracidade dos fatos informados pela empresa auditada. Para tanto, são utilizadas ferramentas que conseguem apontar se as informações são verídicas por meio de documentos que são analisados, demonstrações, e outros documentos ou relatórios utilizados pelas empresas ou mediante informações externas como a confirmação de contas de terceiros, gerando mais credibilidade do que aquelas adquiridas dentro da empresa.

O Conselho Federal de Contabilidade pronuncia, na NBC T 11, a seguinte definição de auditoria:

A auditoria das demonstrações contábeis constitui o conjunto de procedimentos técnicos que tem por objetivo a emissão de parecer sobre a sua adequação, consoante os Princípios Fundamentais de Contabilidade e as Normas Brasileiras de Contabilidade e, no que for pertinente, a legislação específica.

O papel da auditoria para as empresas é de fundamental importância porque, com as informações que são obtidas, os clientes, investidores e outras pessoas interessadas poderão verificar a real situação do empreendimento e tomar suas decisões após analisar os relatórios com o parecer do auditor; após a análise dos dados, decidir pelo investimento ou, até mesmo, por uma possível compra. A ação da auditoria não pode se limitar àquilo que está nos livros oficiais, mas também ao que pode ter sido omitido nos registros principais. Dependendo das circunstâncias vividas pelas empresas, determinados dados podem ter sido omitidos propositadamente dos registros principais [...] (ATTIE, 1998, p. 27).

O Conselho Federal de Contabilidade normatiza a execução dos trabalhos de auditoria por meio da NBC P 1, aprovada pela Resolução CFC n 821/97 e suas interpretações técnicas; da NBC P 3, aprovada pela Resolução CFC n ${ }^{\circ}$ 781/95; da NBC T 11, aprovada pela Resolução CFC $n^{\circ}$ 820/97 e suas interpretações técnicas e da NBC T 12, aprovada pela Resolução CFC no 780/95.

Por intermédio da Resolução CFC n 945/02, foi aprovada a NBC P 4 que dispõe sobre as normas de educação profissional continuada e regulamenta os procedimentos a serem 
A profissão do auditor e o perito contábil na visão dos acadêmicos concluintes do curso

de Ciências Contábeis de universidade pública e privada de Tangará da Serra/MT

Vanderléia Aparecida da Silva; Carlos Edinei de Oliveira; Paulo Guimarães Camelo; Edinéia

Souza Nunes; André Gomes Carvalho

seguidos pelos auditores para que se mantenham constantemente atualizados; o não cumprimento da norma pode vir a acarretar a suspensão do exercício profissional. Recentemente, no entanto, a Resolução CFC n 964/03 aprovou as regras para a revisão externa da qualidade indicando que empresas de auditoria tenham seus trabalhos revisados por seus pares.

Além do CFC, compete à Comissão de Valores Mobiliários (CVM) estabelecer regras para as auditorias executadas nas empresas de capital aberto. As empresas de auditoria que desejam auditar as empresas de capital aberto precisam ter registro junto à CVM bem como seguir as regras estabelecidas por esse órgão. Exceto os trabalhos de auditoria realizados em empresas de capital aberto, os demais trabalhos de auditoria podem ser executados por qualquer contador devidamente registrado no CRC.

Conforme Almeida (1996), com a expansão dos negócios, houve necessidade de dar maior atenção às normas ou aos procedimentos internos. Isso decorreu do fato de que o administrador e, em alguns casos, o proprietário da empresa, não poderiam supervisionar pessoalmente todas as suas atividades; no entanto, da nada valeria a implantação de quaisquer procedimentos internos sem que houvesse um acompanhamento para verificar se eram seguidos pelos empregados da empresa.

\subsubsection{Auditoria Interna}

O auditor interno, diante de todas as informações que tem da empresa e por já estar inserido na organização, poderá detectar com mais facilidade alguma irregularidade que possa ter sido causada por funcionários ou terceiros que venham a prejudicar o patrimônio ou o bom desempenho da organização. Com isso, esse profissional dever ter autoridade para poder analisar todo material que julgar necessário para o bom desempenho de suas atividades e, após isso, poder redefinir os processos, caso seja necessário.

Conforme Almeida (2003, p. 29), a administração da empresa sente a necessidade de dar maior relevância às normas ou aos procedimentos internos, pelo fato de que o administrador, ou o proprietário, não consegue supervisionar pessoalmente todas as atividades, ou seja, pela expansão dos negócios; no entanto, se não houver um acompanhamento, nada vale a implantação desses procedimentos internos. Mesmo como auditor interno, os demais colaboradores da organização não ficam isentos de suas responsabilidades que lhes foram passadas e também de cumprirem suas obrigações. 
A profissão do auditor e o perito contábil na visão dos acadêmicos concluintes do curso de Ciências Contábeis de universidade pública e privada de Tangará da Serra/MT

Vanderléia Aparecida da Silva; Carlos Edinei de Oliveira; Paulo Guimarães Camelo; Edinéia Souza Nunes; André Gomes Carvalho

Segundo Attie (1992), a função da auditoria interna repousa em atividades detalhadas da empresa, relacionadas, de maneira intensa, com o andamento de cada função, área, departamento, setor e operação.

\subsubsection{Auditoria independente ou externa}

A auditoria externa ou independente traz mais credibilidade para os órgãos governamentais, às empresas e também para o público porque não tem vínculo algum com as organizações. Mediante seu parecer, o auditor expõe sua opinião com a veracidade dos fatos obtida a partir de análises documentais ou investigativas e também com uma visão de quem não está inserido na organização.

Segundo Ferreira (2009, p. 01), a auditoria independente ou externa, consiste em técnicas contábeis que têm por objeto outros tipos de procedimentos, como o exame, que é realizado por um auditor independente, com base em livros e documentos de uma empresa, segundo a finalidade constituída por um contrato de prestação de serviços de auditoria.

Segundo o Portal de Contabilidade, o auditor interno ou externo pode emitir os vários tipos de pareceres, quais sejam: sem ressalva, o parecer com ressalva e o parecer com abstenção.

Quadro 1: Abordagem comparativa das diferenças entre auditor interno e auditor externo.

\begin{tabular}{|c|c|}
\hline Auditor Interno & Auditor Ex \\
\hline - É empregado da empresa auditada & $\begin{array}{l}\text { - Não tem vínculo empregatício com a empresa } \\
\text { auditada; }\end{array}$ \\
\hline - Men & IVia \\
\hline - Executa auditoria contábil e & bil; \\
\hline $\begin{array}{l}\text {-Os principais objetivos são: } \\
\text { a)verificar se as normas internas estão sendo } \\
\text { seguidas; } \\
\text { b)verificar a necessidade de aprimorar as normas } \\
\text { internas vigentes; } \\
\text { c) verificar a necessidade de novas normas internas; } \\
\text { d)efetuar auditoria das diversas áreas das } \\
\text { demonstrações contábeis e em áreas operacionais. }\end{array}$ & $\begin{array}{l}\text { - O principal objetivo é emitir um parecer ou opinião } \\
\text { sobre as demonstrações contábeis, no sentido de } \\
\text { verificar se refletem adequadamente a posição } \\
\text { patrimonial e financeira, o resultado das operações, as } \\
\text { mutações do patrimônio líquido e as origens e } \\
\text { aplicações de recursos da empresa examinada }{ }^{6 *} \text {. } \\
\text { Também, se essas demonstrações foram elaboradas de } \\
\text { acordo com os princípios contábeis e se esses }\end{array}$ \\
\hline
\end{tabular}

\footnotetext{
${ }^{6}$ A Demonstração das Origens e Aplicações de Recursos (DOAR) foi substituída pela Demonstração do Fluxo de Caixa (DFC), introduzida pela Lei 11.638/07 que alterou alguns dispositivos da Lei $\mathrm{n}^{\mathrm{o}}$ 6.404/76. Dentre essas alterações, tornou-se também obrigatória a Demonstração do Valor Adicionado (DVA) para as companhias abertas (ALMEIDA, 2003).

Volume 3, Número 6

Revista UNEMAT de Contabilidade

Jul./Dez. 2014

UNEMAT
} 
A profissão do auditor e o perito contábil na visão dos acadêmicos concluintes do curso de Ciências Contábeis de universidade pública e privada de Tangará da Serra/MT

Vanderléia Aparecida da Silva; Carlos Edinei de Oliveira; Paulo Guimarães Camelo; Edinéia Souza Nunes; André Gomes Carvalho

\begin{tabular}{|l|l|}
\hline & $\begin{array}{l}\text { princípios foram aplicados com uniformidade em } \\
\text { relação ao exercício social anterior; }\end{array}$ \\
\hline - Maior volume de testes (possui mais tempo na & - Menor volume de testes, já que o auditor externo \\
empresa para executar os serviços de auditoria). & $\begin{array}{l}\text { está interessado em erros que individual ou } \\
\text { cumulativamente possam alterar de maneira } \\
\text { substancial as informações das demonstrações } \\
\text { contábeis. }\end{array}$ \\
\hline
\end{tabular}

Fonte: ALMEIDA (2003, p. 30).

\subsection{Perícia}

A perícia é uma ferramenta muito importante para o levantamento de informações materiais para as partes que têm interesse. A finalidade desse procedimento é fornecer elementos ao juiz, pois, de posse dessas informações, o julgador poderá tomar as decisões de ambas as partes porque julgam verídicas todas as provas levantadas pelo perito nomeado para o caso.

Existem duas formas de trabalhar com um laudo pericial, que pode ser a perícia solicitada por uma das partes, a perícia requerida; quando é determinada pelo juiz, denominase perícia de ofício. Para Sá (2004), a perícia contábil realiza exames, vistorias, indagações, investigações, avaliações, arbitramentos, procedimentos que são necessários para buscar opinião sobre a questão proposta. A perícia contábil, portanto, é a verificação de todos os fatos ligados ao patrimônio individualizado, buscando oferecer opinião sobre a lide.

O perito faz o levantamento de todas as informações de ambas as partes que a solicitaram, por meio de documentos que são fornecidos pelas partes, de forma amigável ou com solicitação do juiz. O perito precisa ter acesso a todas as informações necessárias para o caso e as partes não podem dificultar o processo; contundo, o quadro 2 demonstra as principais diferenças entre perícia contábil e a auditoria contábil, de uma forma bem explícita.

Quadro 2: Diferenças entre perícia e auditoria

\begin{tabular}{|c|c|c|}
\hline Item de comparação & Perícia & Auditoria \\
\hline Escopo do trabalho & $\begin{array}{l}\text { Deve acompanhar o laudo pericial } \\
\text { com os anexos, para confirmar as } \\
\text { conclusões do perito. }\end{array}$ & $\begin{array}{l}\text { São provas do auditor, não } \\
\text { necessitando de confirmação no } \\
\text { relatório ou no parecer. }\end{array}$ \\
\hline Opinião profissional & $\begin{array}{l}\text { É absoluta, necessária, detalhista, } \\
\text { precisa, direta. }\end{array}$ & $\begin{array}{l}\text { É relativa, observa os aspectos } \\
\text { mais relevantes e materiais. }\end{array}$ \\
\hline Duração do trabalho & $\begin{array}{l}\text { É efêmero. Tem data prevista para } \\
\text { iniciar nem para terminar. Nunca }\end{array}$ & $\begin{array}{l}\text { É continuada. A programação é } \\
\text { previamente definida em períodos }\end{array}$ \\
\hline
\end{tabular}

Volume 3, Número 6

Revista UNEMAT de Contabilidade

Jul./Dez. 2014

UNEMAT 
A profissão do auditor e o perito contábil na visão dos acadêmicos concluintes do curso de Ciências Contábeis de universidade pública e privada de Tangará da Serra/MT

Vanderléia Aparecida da Silva; Carlos Edinei de Oliveira; Paulo Guimarães Camelo; Edinéia Souza Nunes; André Gomes Carvalho

\begin{tabular}{|c|c|c|}
\hline & se repete. Não há perícias iguais & $\begin{array}{l}\text { convenientes. É trabalho repetitivo, } \\
\text { tende a diminuir pelo } \\
\text { conhecimento e pela rotina. }\end{array}$ \\
\hline Relacionamento do trabalho & $\begin{array}{l}\text { Com o juiz, as partes e os peritos } \\
\text { assistentes. }\end{array}$ & $\begin{array}{l}\text { Com toda a equipe do auditado } \\
\text { onde o trabalho for desenvolvido e } \\
\text { os contratantes. }\end{array}$ \\
\hline $\begin{array}{c}\text { Divulgação externa do resultado do } \\
\text { trabalho. }\end{array}$ & É proibida a divulgação. & $\begin{array}{l}\text { Na imprensa escrita, normalmente } \\
\text { em jornal de grande circulação. } \\
\text { Muitas vezes é obrigatória. }\end{array}$ \\
\hline Local de realização do trabalho & $\begin{array}{l}\text { Normalmente no escritório do } \\
\text { perito. }\end{array}$ & $\begin{array}{l}\text { No escritório do auditado ou do } \\
\text { auditor. }\end{array}$ \\
\hline $\begin{array}{c}\text { Divulgação interna do } \\
\text { trabalho }\end{array}$ & $\begin{array}{l}\text { Não é divulgado. Fica à disposição } \\
\text { das partes na justiça. A critério do } \\
\text { perito, pode haver reunião com os } \\
\text { peritos assistentes. }\end{array}$ & $\begin{array}{l}\text { Normalmente, o auditor faz } \\
\text { reunião com a equipe do auditado } \\
\text { ao final do trabalho para colocá-la } \\
\text { a par do resultado da auditoria, } \\
\text { antes da entrega do relatório e do } \\
\text { parecer. }\end{array}$ \\
\hline Autoridade & $\begin{array}{l}\text { Tem a autoridade concedida por lei } \\
\text { ou pelo juiz, no curso do processo } \\
\text { da perícia judicial. }\end{array}$ & $\begin{array}{l}\text { Não tem autoridade concedida pela } \\
\text { entidade auditada. }\end{array}$ \\
\hline Método da pesquisa & Universalidade dos fatos & $\begin{array}{l}\text { Amostragem, confiabilidade nos } \\
\text { controles internos, podendo ter a } \\
\text { universalidade dos fatos. }\end{array}$ \\
\hline Objeto da pesquisa & $\begin{array}{l}\text { Emite opinião por meio da } \\
\text { produção de prova pericial (laudo } \\
\text { pericial) conforme sua convicção } \\
\text { nas provas encontradas. }\end{array}$ & $\begin{array}{l}\text { Emite opinião conforme provas } \\
\text { produzidas pelos exames de } \\
\text { auditoria. }\end{array}$ \\
\hline Período da realização do trabalho & $\begin{array}{l}\text { A oportunidade é determinada pelo } \\
\text { magistrado ou requerida pelas } \\
\text { partes para a produção de provas } \\
\text { em período certo do processo, com } \\
\text { prazo determinado por uma única } \\
\text { vez. }\end{array}$ & $\begin{array}{l}\text { Normalmente, é realizado em } \\
\text { períodos regulares, para } \\
\text { atendimento estatutário ou legal, e } \\
\text { repete-se na mesma periodicidade. }\end{array}$ \\
\hline
\end{tabular}

Fonte: MORAIS; FRANÇA (2004, p. 61, 63).

Conforme visto no quadro 2, as duas áreas de atuação são completamente distintas, por isso é muito difícil exercer as duas profissões sem que uma atrapalhe a outra.

\section{METODOLOGIA}


A profissão do auditor e o perito contábil na visão dos acadêmicos concluintes do curso

de Ciências Contábeis de universidade pública e privada de Tangará da Serra/MT

Vanderléia Aparecida da Silva; Carlos Edinei de Oliveira; Paulo Guimarães Camelo; Edinéia

Souza Nunes; André Gomes Carvalho

Para obter os dados que compõem este artigo, foi utilizada a pesquisa quantitativa em uma universidade pública e em uma universidade particular de Tangará da Serra-MT. Foram entregues questionários para dez alunos de cada turma, a fim de obter uma opinião formada de todos sobre o tema escolhido para pesquisa e, com isso, fazer uma completa análise de forma detalhada das informações obtidas por meio dos questionários.

A pesquisa também foi realizada por intermédio de dados bibliográficos coletados em livros de pesquisa e pela leitura de artigos específicos no meio eletrônico, por meio de sites conceituados, relacionados ao tema.

Delimitou-se o espaço de análise interpretação e conclusão, com relação ao tempo, no período de março a abril de 2012. Com relação ao objeto, delimitou-se a pesquisa nas universidades, localizadas na cidade de Tangará da Serra, com graduandos de oitavo semestre do curso de Ciências Contábeis.

\section{RESULTADOS E DISCUSSÃO}

Quanto à forma de desenvolvimento do artigo, não se teve a intenção de expressar indiferença quanto às instituições, mas sim ter uma opinião formada dos alunos para que se possa ter um entendimento quanto ao tema. Igualmente, verificar se as grades curriculares estão proporcionando conhecimento aos graduandos para, quando finalizarem a graduação, poderem optar por uma das duas áreas de atuação com conhecimento necessário para dar início à carreira profissional.

Após adquirir o relatório, que contém a grade curricular do curso de ambas as instituições, foi elaborado um questionário a que os alunos responderam no período de 25 de março de 2012 até o dia 06 de abril de 2012. Participaram dez alunos de cada turma do oitavo semestre do curso de Ciências Contábeis, de uma universidade privada e de outra pública, ou seja, de forma aleatória.

Tabela 1 - Profissionais habilitados e capacitados para suprir o crescimento mercado de trabalho de peritos e auditores?

\begin{tabular}{|c|c|c|}
\hline $\begin{array}{c}\text { UNIVERSIDADES } \\
\text { E } \\
\mathrm{N}^{\circ} \text { DE ALUNOS }\end{array}$ & SIM & NÃO \\
\hline PÚBLICA - 10 & 2 & 8 \\
\hline PRIVADA - 10 & 5 & 5 \\
\hline
\end{tabular}

Fonte: Dados da pesquisa. 
A profissão do auditor e o perito contábil na visão dos acadêmicos concluintes do curso de Ciências Contábeis de universidade pública e privada de Tangará da Serra/MT

Vanderléia Aparecida da Silva; Carlos Edinei de Oliveira; Paulo Guimarães Camelo; Edinéia Souza Nunes; André Gomes Carvalho

Na tabela 1, verifica-se que a maioria dos alunos da universidade pública considera que, no cenário atual, não existem profissionais suficientes para atender o mercado crescente e que não estão preparados e nem capacitados. Os dados coletados na universidade privada demonstram que as opiniões ficaram equilibradas; mas, devido às informações da mídia, pode-se afirmar que é um mercado promissor, que está carente de profissionais com experiência no mercado atual.

Tabela 2 - Durante a formação acadêmica foi realizado alguma atividade relacionada à área de perícia contábil?

\begin{tabular}{c|c|c}
\hline $\begin{array}{c}\text { UNIVERSIDADES } \\
\text { E } \\
\mathrm{N}^{\mathrm{o}} \text { DE ALUNOS }\end{array}$ & SIM & NÃO \\
\hline PÚBLICA -10 & 2 & 8 \\
\hline PRIVADA -10 & 7 & 3 \\
\hline
\end{tabular}

Fonte: Dados da pesquisa.

Mesmo sendo uma área carente de bons profissionais, verificou-se que, segundo os alunos da universidade privada, a maioria teve conhecimento e executou atividades relacionadas à área de perícia contábil. Na instituição pública, a minoria teve acesso a esse conhecimento, portanto conclui-se que, mesmo em menor quantidade, houve atividades relacionadas ao conteúdo. O domínio dessa área do curso de Ciências Contábeis pode facilitar na escolha da profissão, levando o contabilista a ser um futuro perito contábil.

Tabela 3 - Durante a formação acadêmica foi realizado alguma atividade relacionada à área de auditoria contábil?

\begin{tabular}{c|c|c}
\hline $\begin{array}{c}\text { UNIVERSIDADES } \\
\text { E } \\
\mathrm{N}^{\mathrm{D}} \text { DE ALUNOS }\end{array}$ & SIM & NÃO \\
\hline PÚBLICA -10 & 6 & 4 \\
\hline PRIVADA -10 & 8 & 2 \\
\hline
\end{tabular}

Fonte: Dados da pesquisa.

Quanto à auditoria, é possível averiguar que é um conteúdo mais presente nas grades curriculares das universidades, por isso a maioria dos alunos teve atividades relacionadas ao tema, habilitando-os quando tiverem oportunidade de desenvolver algum trabalho em determinadas empresas.

Para que isso seja possível, os alunos não devem ficar restritos às aulas da universidade, mas procurarem se aperfeiçoar no assunto. Quando finalizarem a graduação, 
A profissão do auditor e o perito contábil na visão dos acadêmicos concluintes do curso de Ciências Contábeis de universidade pública e privada de Tangará da Serra/MT

Vanderléia Aparecida da Silva; Carlos Edinei de Oliveira; Paulo Guimarães Camelo; Edinéia Souza Nunes; André Gomes Carvalho

poderão cursar uma especialização na área para facilitar o início na nova profissão, garantindo mais conhecimento especifico por meio de especializações profissionais, principalmente focando na área de auditoria e pericia contábil.

Tabela 4 - Você considera os conceitos apresentados na graduação suficientes para iniciar-se na profissão de perito ou auditor?

\begin{tabular}{c|c|c}
\hline $\begin{array}{c}\text { UNIVERIDADES } \\
\text { E }\end{array}$ & SIM & NÃO \\
No DE ALUNOS & 1 & 9 \\
\hline PÚBLICA -10 & 5 & 5 \\
\hline PRIVADA -10 & & 5 \\
\hline
\end{tabular}

Fonte: Dados da pesquisa.

A tabela 4 demonstra que a maioria dos alunos não considera os métodos apresentados na graduação suficientes para iniciar na profissão. Diante dessa lacuna, podem não sair preparados para candidatarem-se como bons profissionais de auditoria ou perícia contábil, visto que os conceitos apresentados não atenderam todos os requisitos para que possam dar o primeiro passo na profissão de perito ou auditor.

Tabela 5 - Você considera o mercado de trabalho promissor para quem deseja ingressar na área de perito ou auditor?

\begin{tabular}{c|c|c}
\hline $\begin{array}{c}\text { UNIVERSIDADES } \\
\text { E } \\
\mathrm{N}^{\mathrm{D}} \text { DE ALUNOS }\end{array}$ & SIM & NÃO \\
\hline PÚBLICA -10 & 10 & 0 \\
\hline PRIVADA -10 & 7 & 3 \\
\hline
\end{tabular}

Fonte: Dados da pesquisa.

Conforme demonstra a tabela 5 , todos os alunos da universidade pública e a maioria da universidade privada concorda que as profissões em questão têm um vasto mercado de trabalho. Podem, portanto, ser uma grande oportunidade para, quando finalizarem a graduação, optar por essas áreas desde que saiam com bagagem de conhecimento suficiente para, como um bom profissional, poder dar início à carreira.

Tabela 6 - Em sua opinião, as profissões de perito e de auditor são bem remuneradas?

\begin{tabular}{c|c|c}
\multicolumn{1}{c}{ Tabela 6 - Em Sua opinião, as profissões de perito e de auditor são bem remuneradas? } \\
\hline UNIVERSIDADES & SIM & NÃO \\
E & & \\
$\mathrm{N}^{\mathbf{o}}$ DE ALUNOS & & \\
\hline
\end{tabular}


A profissão do auditor e o perito contábil na visão dos acadêmicos concluintes do curso de Ciências Contábeis de universidade pública e privada de Tangará da Serra/MT

Vanderléia Aparecida da Silva; Carlos Edinei de Oliveira; Paulo Guimarães Camelo; Edinéia Souza Nunes; André Gomes Carvalho

\begin{tabular}{c|c|c}
\hline PÚBLICA -10 & 10 & 0 \\
\hline PRIVADA -10 & 8 & 2 \\
\hline
\end{tabular}

Fonte: Dados da pesquisa.

Além de serem profissões com vasto mercado, verifica-se que também oferecem uma ótima remuneração conforme afirmaram os alunos. Devido a essas respostas, pode-se concluir que pode haver maior procura por causa do retorno financeiro, que é muito atrativo.

Tabela 7 - Você sabe o que faz um perito?

\begin{tabular}{|c|c|c|}
\hline $\begin{array}{c}\text { UNIVERSIDADES } \\
\text { E } \\
\mathrm{N}^{\mathrm{o}} \text { DE ALUNOS }\end{array}$ & SIM & NÃO \\
\hline PÚBLICA - 10 & 8 & 2 \\
\hline PRIVADA - 10 & 10 & 0 \\
\hline
\end{tabular}

Fonte: Dados da pesquisa.

Portanto, mesmo não tendo muitos profissionais peritos, quase todos os alunos sabem o que fazem, por isso é uma profissão em ascensão e com grandes oportunidades de trabalho.

O Portal de Contabilidade menciona que perícia contábil, cada vez mais, vem atraindo a atenção dos profissionais da Contabilidade, pois é uma área que necessita de constante aprimoramento de conhecimento. Para a solução de litígios na justiça, o trabalho do perito contador é essencial; pode ser contratado pelas partes ou indicado pelo juiz para elaborar laudo sobre um determinado caso. Para ser um perito contador, o profissional deve estar regularmente registrado em Conselho Regional de Contabilidade (CRC) de seu Estado; dessa forma, está apto a exercer a profissão de perito contador, ou seja, tem que ser especialista na causa a ser periciada.

Tabela 8 - Você sabe o que faz um auditor?

\begin{tabular}{c|c|c}
\hline $\begin{array}{c}\text { UNIVERSDADS } \\
\text { N }^{\circ} \text { DE ALUNOS }\end{array}$ & SIM & NÃO \\
\hline PÚBLICA -10 & 10 & 0 \\
\hline PRIVADA -10 & 10 & 0 \\
\hline
\end{tabular}

Fonte: Dados da pesquisa.

A profissão de auditor é mais conhecida porque todos os alunos sabem o que faz esse profissional. Devido às oportunidades e ao vasto mercado de trabalho para auditor, pode-se concluir que, após finalizarem a graduação, poderá haver uma maior procura por essa área. 
A profissão do auditor e o perito contábil na visão dos acadêmicos concluintes do curso de Ciências Contábeis de universidade pública e privada de Tangará da Serra/MT

Vanderléia Aparecida da Silva; Carlos Edinei de Oliveira; Paulo Guimarães Camelo; Edinéia Souza Nunes; André Gomes Carvalho

Para que isso aconteça, os alunos precisam fazer uma especialização para se aperfeiçoarem na carreira e tornarem-se profissionais bem-sucedidos e renomados devido às grandes oportunidades que o mercado oferece.

Tabela 9 - Em sua opinião, é possível exercer as duas profissões?

\begin{tabular}{c|c|c}
\hline $\begin{array}{c}\text { UNIVERSIDADES } \\
\text { E } \\
\text { No DE ALUNOS }\end{array}$ & SIM & NÃO \\
\hline PÚBLICA -10 & 5 & 5 \\
\hline PRIVADA -10 & 6 & 4 \\
\hline
\end{tabular}

Fonte: Dados da pesquisa.

Conforme as respostas dadas, a maioria acredita que dá para exercer as duas carreiras, mas sabe-se que são duas profissões distintas e, com a execução das duas ao mesmo tempo, pode ficar difícil conciliá-las e, devido a isso, perder-se um pouco a qualidade dos trabalhos. Não é impossível que consigam conciliar as duas profissões, contudo é um pouco improvável, ou seja, no mercado atual não se conhece algum profissional que atue nas duas áreas tanto como auditor e como perito simultaneamente.

Tabela 10 - Em sua opinião, as aulas de auditoria e perícia podem ser consideradas relevantes para formação acadêmica?

\begin{tabular}{c|c|c}
\hline $\begin{array}{c}\text { UNIVERIDADES } \\
\text { E } \\
N^{\text {o }} \text { DE ALUNOS }\end{array}$ & SIM & NÃO \\
\hline PÚBLICA -10 & 9 & 1 \\
\hline PRIVADA -10 & 7 & 3 \\
\hline
\end{tabular}

Fonte: Dados da pesquisa.

Pelas respostas dos alunos, conforme demonstrado nas outras tabelas, as grades curriculares não oferecem muitas práticas das matérias selecionadas para este estudo; mas a maioria deles considera-as como temas relevantes para formação acadêmica e também podendo ser suas futuras profissões. Para que isso aconteça, no entanto, as instituições devem dar mais ênfase a essas matérias e aumentar os exercícios práticos.

\section{CONSIDERAÇÕES FINAIS}

Após o estudo realizado, chega-se à conclusão de que a auditoria e a perícia são de fundamental importância para as empresas e toda a sociedade, cada uma com seu papel e propósito. A auditoria auxilia as empresas ao indicar diretrizes para cumprimento de normas, legislação e controles internos por intermédio da análise dos documentos fornecidos e 
A profissão do auditor e o perito contábil na visão dos acadêmicos concluintes do curso de Ciências Contábeis de universidade pública e privada de Tangará da Serra/MT

Vanderléia Aparecida da Silva; Carlos Edinei de Oliveira; Paulo Guimarães Camelo; Edinéia Souza Nunes; André Gomes Carvalho

avaliação da empresa. Além disso, pode sugerir melhorias diante das evidências, experiências e conhecimento da empresa analisada, ocasionando até mesmo redução de custos e melhoria de processos. Já a perícia auxilia o juiz quando da busca da verdade sem interferência da vontade das partes, ou seja, ajuda a fazer justiça.

O perito deve buscar elementos de prova que garantam $100 \%$ a efetividade da decisão relatada no laudo, não trabalha com probabilidades ou amostragens. Além disso, o laudo pericial não é divulgado e interessa somente às partes envolvidas e ao juiz, portanto considera-se que não existe qualquer semelhança entre os objetivos da auditoria e da perícia. A perícia auxilia o juiz a tomar decisões; a auditoria, o cumprimento de legislação comercial, por isso as profissões de auditor contábil e de perito contábil necessitam de profissionais à altura da complexidade que a profissão exige como atualização constante e muito estudo.

Por intermédio dos questionários, conclui-se que foi respondida a questão, que era saber como estavam o ensinamento dessas matérias nas grades curriculares das universidades pesquisadas. Igualmente, também saber como os alunos enxergam essas profissões e, na visão deles, como as avaliam e as oportunidades que têm no mercado atual.

A conclusão a que se chegou após a pesquisa foi que os alunos consideram as profissões como promissoras e com grandes oportunidades; porém, segundo eles, a formação acadêmica não lhes proporciona práticas para que possam conhecer aprofundadamente as carreiras que podem optar após a formação. Quase todos sabem o que faz um perito e um auditor e isso pode facilitar quando da escolha da profissão. Quanto à limitação da pesquisa, encontrou-se dificuldade de aplicar o questionário na universidade privada, pois a instituição demorou para autorizar esta pesquisa, chegando ao ponto de a pesquisadora achar que não seria realmente possível.

Sugere-se, para futuras pesquisas, diagnosticar, no fórum do município de Tangará da Serra-MT, os peritos que são auxiliares da justiça neste município.

\section{REFERÊNCIAS}

ALMEIDA, Marcelo Cavalcanti. Auditoria: um curso moderno e completo. 5. ed. São Paulo: Atlas, 1996.

Auditoria: um curso moderno e completo. 6. ed. São Paulo: Atlas, 2003. 
A profissão do auditor e o perito contábil na visão dos acadêmicos concluintes do curso de Ciências Contábeis de universidade pública e privada de Tangará da Serra/MT

Vanderléia Aparecida da Silva; Carlos Edinei de Oliveira; Paulo Guimarães Camelo; Edinéia Souza Nunes; André Gomes Carvalho

ATTIE, Willian. Auditoria interna. São Paulo: Atlas, 1992.

Auditoria: Conceitos e aplicações. 3. ed. São Paulo: Atlas, 1998.

CFC - Conselho Federal de Contabilidade. Resoluções CFC n.858/99 e n. 820/97.

. Fiscalização ética e disciplina. Disponível em:

<http://portalcfc.org.br/coordenadorias/fiscalizacao/faq/faq.php?id=6409>. Acesso em: 25 abr. 2013.

Clube dos Contadores - Diferença entre auditoria e perícia contábil. Disponível em: <http://www.clubedoscontadores.com.br/_artigos_olha.php?art=216\&mod=1 > . Acesso em: 04 abr. 2013.

CREPALDI, Silvio Aparecido. Auditoria contábil: teoria e prática. 7. ed. São Paulo: Atlas, 2011.

FERREIRA, Ricardo J. Manual de auditoria. 7. ed. Rio de Janeiro: Ferreira 2009.

MORAIS, Antônio Carlos; FRANÇA, José Antônio de. Perícia judicial e extrajudicial: uma abordagem conceitual e prática. 2. ed. Brasília: A.C. Morais, J. A. de França, 2004.

PORTAL de Contabilidade. Auditoria independente: características. Disponível em: <http://www.portaldecontabilidade.com.br/tematicas/auditoria.htm>. Acesso em: $25 \mathrm{abr}$. 2013.

Perícia contábil: um mercado em expansão. Disponível em: <http://www.portaldecontabilidade.com.br/tematicas/trabalhopericial.htm>. Acesso em: 21 abr. 2013.

SÁ, Antônio Lopes de. Perícia contábil. 3. ed. São Paulo: Atlas, 2004. 